\title{
An Auto-amylo-alkali Viscograph, Titration Viscograph for Starch Pasting ${ }^{\dagger}$
}

\author{
By Hisaya HoriuchI \\ National Food Research Institute, Ministry of Agriculture \\ and Forestry, Tokyo
}

Received March 6, 1972

Swelling of starch granules with certain bases, salts and organic reagents at room temperature-cold gelatinization ${ }^{13}$ has been mainly aimed to compare with the activities of these reagents. Mangels" studied the gelatinizing activities of various reagents on wheat starch, as influenced by concentration of reagent. And the study was by means of determination of viscosity after sufficient period for swelling. The concept had been developed by Suzuki ${ }^{3)}$ for the studies of differences among various starches, and had been established as the amylo-alkali viscography, in which the concentration of potassium hydroxide solution was increased continuously in the same starch suspension. This method has been applied to several starches, ${ }^{4)}$ and different informations from that by heat pasting such as Brabender amylograph were obtained. The method of Suzuki, ${ }^{31}$ using simple apparatus, presented some difficulties with an intricate procedure and a long measuring time by manual operation throughout the determination. This note deals with an attempt to develop the alkali viscography into the continuous recording and automatic operating method.

The apparatus was composed of following three parts as shown in Fig. 1. Vibratingplate viscometer (Toshiba VV-1A Special type) was employed. The main features of the visco-

+ This report was presented at the Annual Meeting of the Agricultural Chemical Society of Japan on April 1968. meter are in that it enables the determination in a small quantities of fluid and the response to a wide range of viscosity. The mechanisms are as follows; when the disk probe (1) of $5 \mathrm{~mm}$

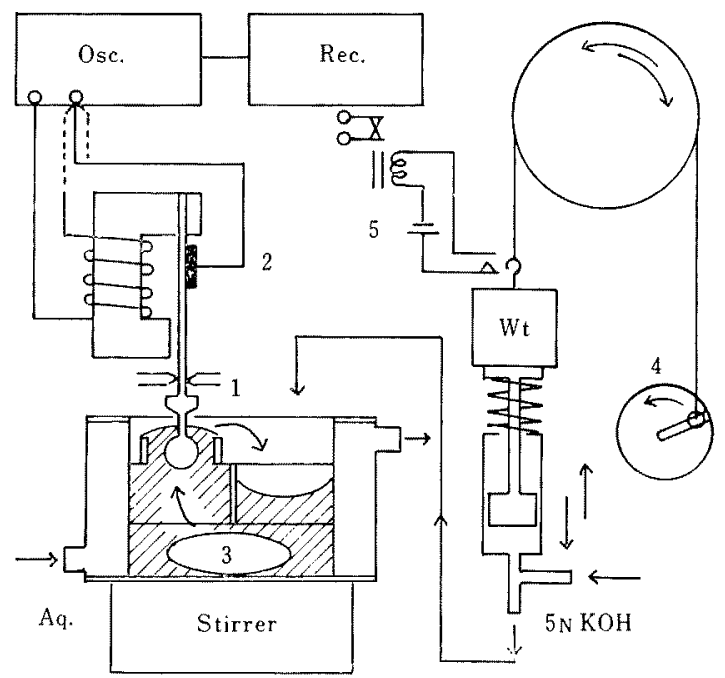

FIG. 1. Schematic Drawing of the Apparatus.

Osc., Oscillator of the viscometer; Rec., Recorder; Wt., Weight fitted with the automatic pipette; Aq., Heating jacket; 1, Probe of the viscometer; 2, Transducer; 3, Stirring rod; 4, Crank; 5, Time marker; Hatching part of the cup shows the spouting suspension.

in diameter with an electro-magnetic vibration at about $600 \mathrm{cps}$ is immersed in luquid, the decrease of vibrating displacement due to viscosity of the liquid is detected with a piezoelectric transducer (2) attached to another end of the probe. The microammeter reading 
was converted into the viscosity value $(\mathrm{cp} \cdot \mathrm{g} /$ $\mathrm{cm}^{3}$ ) with calculation curve. The viscosity was recorded on $10 \mathrm{mV}$ self-balancing recorder. The measurement was accurate within $5 \%$ in $10 \sim 100 \mathrm{cp}$ of liquid.

A $100 \mathrm{ml}$ circulatory cup made of plastics was designed to maintain a certain spouting level of starch suspension without regard to increase of the volume due to addition of $\mathrm{KOH}$ solution. It was observed in preliminary test that the suspension is spouting from a discharge tube by centrifugal force due to rotation of a stirring rod (3) in the closed cup as well as the mechanism of centrifugal pump. Moreover, the spouting level does not depend on the volume but depend upon the stirring speed of the rod.

As a solution of some problems concerning the addition of $\mathrm{KOH}$ solution, e.g., periodical addition, low stroke speed, high accuracy and easy wash and so on, a $0.5 \mathrm{ml}$ plunger type automatic pipette was converted into an electromotive pump.** In Fig. 1, if a radius of the crank (4) was set up larger than the half stroke of the plunger, $0.1 \sim 0.45 \mathrm{ml}$ of $\mathrm{KOH}$ solution could be added periodically at intervals of $10 \sim 300 \mathrm{sec}$ through the upand-down motions of a spring and a weight fitted with the plunger. The result of standarization test of the plunger volume with water was accurate within $\pm 1.5 \%$ during the opera-

Table I. Effect of Vibrating Amplitude OF THE PROBE

$2.5 \%$ Non-waxy rice starch, $30^{\circ} \mathrm{C}, 0.35 \mathrm{ml} / \mathrm{min}$.

\begin{tabular}{clll}
\hline Amplitude & \multicolumn{1}{c}{ Geln..$^{a !}$} & \multicolumn{2}{c}{ Peak viscosity } \\
\hline No. $1(0.04 \mathrm{~mm})$ & $0.31 \mathrm{~N}^{b)}$ & $0.43 \mathrm{~N}^{b 1}$ & $27 \mathrm{cp} \cdot \mathrm{g} / \mathrm{cm}^{3}$ \\
$3(0.08)$ & 0.31 & 0.45 & 28 \\
$5(0.12)$ & 0.31 & 0.45 & 16 \\
\hline
\end{tabular}

a) Initial rise in viscosity.

b) Alkalinity at the respective points.

** At present, electromotive burette (MetrohmDosimat) is employed together with a rotary switch as a more sensitive and compact instrument. tion. The number of stroke of the plunger was recorded on the same chart with a time marker (5). The added volume of $5 \mathrm{~N} \mathrm{KOH}$ (a) was converted into the normality of $\mathrm{KOH}$ (N) in the suspension as follows, ${ }^{3}$

$$
\mathrm{N}=5 a /(V+a) \quad V \text { : initial volume }
$$

Examination of operating conditions. In the determination of $60 \%$ cane sugar solution as a standard matter for viscometry, the viscosity reading fluctuated within $\pm 1 \sim 2 \%$, according to the change of the liquid level within $\pm 2.5 \mathrm{~mm}$ to the probe. In the fluid on a magnetic stirrer, the reading is stabilized at high speed rotation of the rod but it rather fluctuated with the same period of the stirrer at low speed rotation. Furthermore, it is not affected by the speed and the direction of the current against the probe. On the actural viscogram with rice starch suspension, smooth base line was obtained at larger extent of the vibrating amplitude but peak viscosity decreased (Table I). The concentrations of $\mathrm{KOH}$ solution at gelatinization and peak viscosity (geln. $\mathrm{KOH}$ and peak $\mathrm{KOH}$ ) showed the same value at any three amplitudes.

When $5 \mathrm{~N} \mathrm{KOH}$ solution was added periodically by small quantities, the number of plunger stroke reached at geln. $\mathrm{KOH}$ required more than that by large quantities, but the normality of $\mathrm{KOH}$ at the point showed lower value as given in Table II. Peak viscosity appeared at the same concentration of $\mathrm{KOH}$ in any volume, though a rather flat peak was obtained on addition by small quantities.

When the reagent was added periodically at longer intervals, geln. or peak $\mathrm{KOH}$ and peak viscosity showed lower values as given in Table III. Moreover, it seems likely that these values will converge to certain values respectively. Recently, Sato ${ }^{5}$ studied critical concentration of $\mathrm{NaOH}$ for the pasting by a similar method to that of Mangels. ${ }^{2}$ It is difficult, however, to obtain a convergent value 
Table II. Effect of Addition Vol, of KOH per Stroke $2.5 \%$ Non-waxy rice starch, $30^{\circ} \mathrm{C}, 60 \mathrm{sec} / \mathrm{stroke}$, Amplitude No. 3 .

\begin{tabular}{|c|c|c|c|c|c|}
\hline \multirow{2}{*}{$\begin{array}{l}\text { Vol./Stroke } \\
\qquad(\mathrm{ml})\end{array}$} & \multicolumn{2}{|c|}{ Geln. ${ }^{a l}$} & \multicolumn{3}{|c|}{ Peak viscosity } \\
\hline & $(\text { stroke })^{b}$ & $(\mathrm{~N})^{\mathrm{c})}$ & $(\text { stroke })^{b)}$ & $(\mathrm{N})^{e l}$ & $\left(\mathrm{cp} \cdot \mathrm{g} / \mathrm{cm}^{3}\right)$ \\
\hline 0.35 & 8 & 0.33 & 16 & 0.45 & 28 \\
\hline 0.25 & 10 & 0.31 & 23 & 0.45 & 25 \\
\hline 0.15 & 14 & 0.30 & 38 & 0.45 & 25 \\
\hline
\end{tabular}

a) Initial rise in viscosity.

b) Numbers of the plunger stroke by the respective points.

b) Alkalinity at the respective points.

Table III. EFFECT OF Addition Interval of $\mathrm{KOH}$

$2.5 \%$ Non-waxy rice starch, $30^{\circ} \mathrm{C}, 0.35 \mathrm{ml} / \mathrm{stroke}$, Amplitude No. 3.

\begin{tabular}{clll}
\hline Interval & Geln. $^{\alpha}$ & \multicolumn{2}{l}{ Peak viscosity } \\
\hline $10 \mathrm{sec}$ & $0.39 \mathrm{~N}^{b}$ & $0.63 \mathrm{~N}^{b /}$ & $33 \mathrm{cp} \cdot \mathrm{g} / \mathrm{cm}^{3}$ \\
30 & 0.33 & 0.49 & 30 \\
60 & 0.31 & 0.45 & 28 \\
120 & 0.31 & 0.42 & 22 \\
300 & 0.30 & 0.42 & 21 \\
\hline
\end{tabular}

a) Initial rise in viscosity.

b) Alkalinity at the respective points.

on a continuous determination. Accordingly, it is necessary to add the reagent with strictly appointed condition for the determination of geln. or peak $\mathrm{KOH}$.

Being raised the temperature on the determination, the geln. $\mathrm{KOH}$ decreased irrespective of the addition interval of the reagent, as shown in Table IV. While the peak $\mathrm{KOH}$ was observed almost the same value on a lower addition speed. It seems that both geln. and peak $\mathrm{KOH}$ will converge to certain values respectively on a lower addition speed or a higher temperature. However, high temperature over $40^{\circ} \mathrm{C}$ can not actually be used, because of an unsuitable curve with low and flat peak due to the characteristics of the transducer.

The suspension displays higher viscosity at the peak when the initial starch concentration was increased, as shown in Fig. 2. The
Table IV. Temperature Dependence on the VISCOGRAPHY

$2.5 \%$ Non-waxy rice starch, $0.35 \mathrm{ml} / \mathrm{stroke}$, Amplitude No. 3.

\begin{tabular}{|c|c|c|c|c|}
\hline \multirow{2}{*}{$\begin{array}{l}\text { Temp. } \\
20^{\circ} \mathrm{C}\end{array}$} & \multirow{2}{*}{$\begin{array}{c}\text { Interval } \\
10 \mathrm{sec}\end{array}$} & \multirow{2}{*}{$\begin{array}{l}\text { Geln. }{ }^{a)} \\
0.39 \mathrm{~N}^{b)}\end{array}$} & \multicolumn{2}{|c|}{ Peak viscosity } \\
\hline & & & $0.57 \mathrm{~N}^{b}$ & $29 \mathrm{cp} \cdot \mathrm{g} / \mathrm{cm}^{3}$ \\
\hline & 60 & 0.33 & 0.45 & 29.5 \\
\hline & 120 & 0.33 & 0.42 & 29.5 \\
\hline \multirow[t]{3}{*}{30} & 10 & 0.39 & 0.63 & 33 \\
\hline & 60 & 0.31 & 0.45 & 28 \\
\hline & 120 & 0.31 & 0.42 & 21.5 \\
\hline \multirow[t]{3}{*}{40} & 10 & 0.36 & 0.55 & 30 \\
\hline & 60 & 0.28 & 0.43 & 24 \\
\hline & 120 & 0.28 & 0.42 & 23 \\
\hline & & & & \\
\hline
\end{tabular}

logarithm of peak viscosity was directly relative to the logarithm of the starch concentration, as the relation has been indicated on the heat viscography. ${ }^{6)}$ While, the data of the geln. $\mathrm{KOH}$ were obtained the same value irrespective of the starch concentration, as a report by light-scattering alkali viscography. ${ }^{\text {? }}$

As the result of the above mentioned experiments, the optimum operating conditions were decided as follows: initial starch concentration, $2.5 \%$; temperature, $30^{\circ} \mathrm{C}$; vibrating amplitude, No. 3 ; addition volume, $0.35 \mathrm{ml}$ of $5 \mathrm{~N} \mathrm{KOH}$ per stroke; addition interval, $1 \mathrm{~min}$; equal rate of increasing by $0.014 \sim$ $0.017 \mathrm{~N} / \mathrm{min}$. 


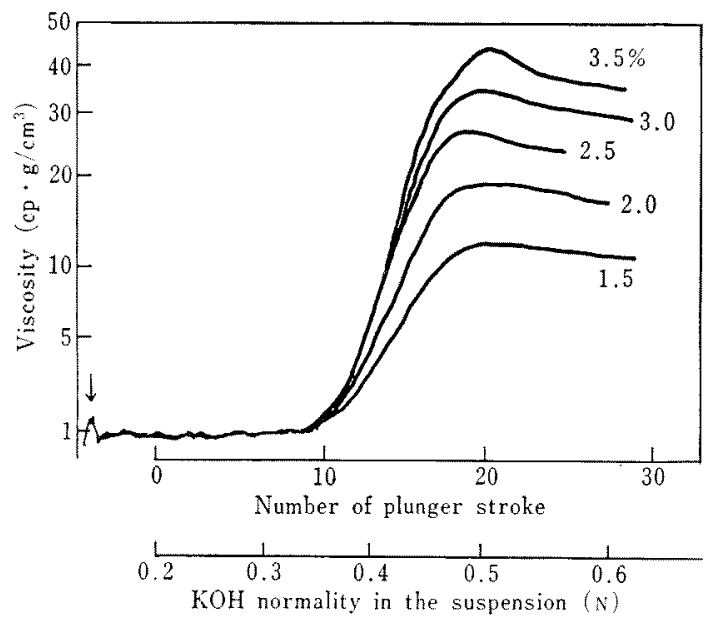

FIG. 2. Effect of Initial Starch Concentration on the Alkali Viscogram.

Non-waxy rice starch, $0.35 \mathrm{ml} / \mathrm{min}, 30^{\circ} \mathrm{C}, \downarrow$ Previous addition to $0.2 \mathrm{~N}$

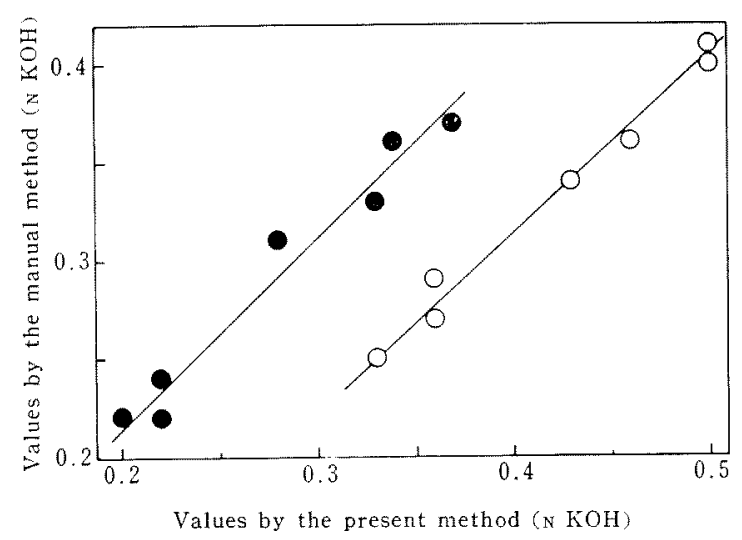

FIG. 3. Comparison between the Manual and the Present Method by Use of Non-Waxy Rice Starches. ${ }^{81}$

- Concn. of $\mathrm{KOH}$ soln. at gelatinized point, $\mathrm{O}$ Conc. of $\mathrm{KOH}$ soln. at peak viscosity

Comparison with the manual method. The same starch samples examined in the previous report $^{8 /}$ by manual method ${ }^{3 /}$ were determined again by the present method under the conditions as decided above. Relation between both methods on geln. and peak $\mathrm{KOH}$ are shown in Fig. 3, hough not presented in every datum. A very high correlationship was found but no identical value in both methods was given. The low values of peak $\mathrm{KOH}$ on the manual method were due to a low rate of increasing of alkalinity. Some fluctuation of geln. $\mathrm{KOH}$ was due to reading of a slightly higher point over the base line on the previous report. Peak viscosity could not directly be compared in both methods because of different dimensions and frequencies, but there were similar trends of differences among the samples.

Alkali viscography of yarious starches. Figure 4 shows alkali viscograms of various commercial starches determined under the conditions as decided above, except that the initial concentration of potato starch was decreased, because it already gelled at $2.5 \%$. Geln. and peak $\mathrm{KOH}$ of potato starch may be compared, however, with that of the other starches, because the starch concentration have no effect on these characteristic $\mathrm{KOH}$ normalities as mentioned above. It is interesting to learn different order of gelatinization point among the starches from that on the heat viscogram. For instance, gelatinization point of sweet potato starch should be positioned in reverse order against wheat or pea starches on the heat viscogram.

Table $\mathrm{V}$ shows the data of various treated starches. There was no difference in geln. $\mathrm{KOH}$ on this viscogram between the rice starch purified by sonic treatment and the starch by dilute alkali method, while a marked difference in pasting temperature on the heat viscogram was found between them. ${ }^{9}$ Geln. $\mathrm{KOH}$ of the starch defatted with $85 \%$ hot methanol decreased as well as in heat viscogram. On the contrary, the value of soluble starch made from potato starch was greater than that of the raw starch.

The cold gelatinization of starch in aqueous alkali solution showed different response from 


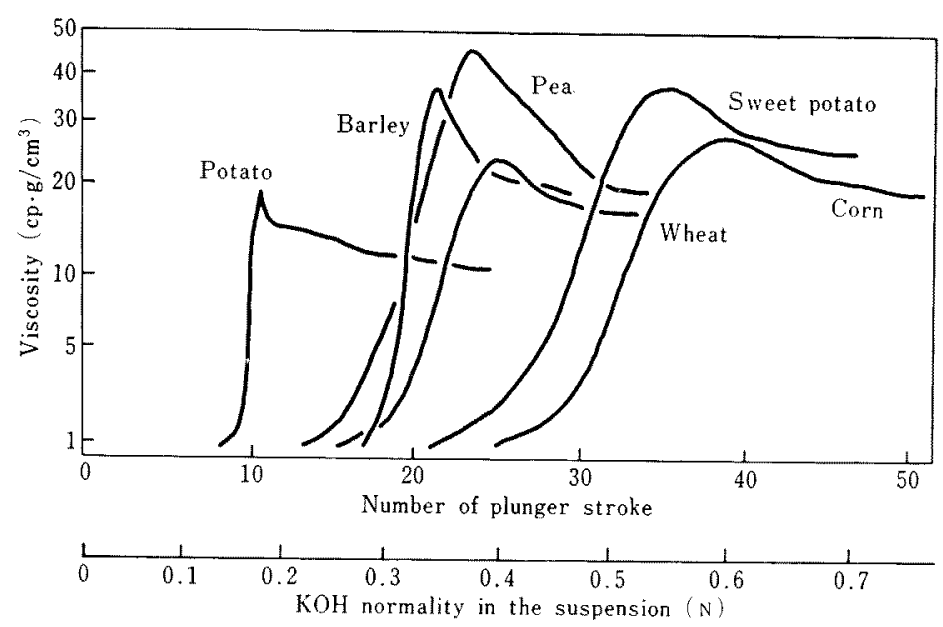

FIG. 4. Alkali Viscograms of Various Starches.

$2.5 \%$ (Potato $1.5^{\circ} \%$ ), $30^{\circ} \mathrm{C}, 0.35 \mathrm{ml} /$ stroke (min).

Table V. Alkali Viscograms of Treated RICE STARCHES

$2.5 \%$ Non-waxy rice, $30^{\circ} \mathrm{C}, 0.35 \mathrm{ml} / \mathrm{min}$, Amplitude No. 3

\begin{tabular}{llll}
\hline \multicolumn{1}{c}{ Sample } & Geln. ${ }^{a)}$ & \multicolumn{2}{c}{ Peak viscosity } \\
\hline Alkali method starch & $0.28 \mathrm{~N}^{b /}$ & $0.415 \mathrm{~N}^{b}$ & $28 \mathrm{cp} \cdot \mathrm{g} / \mathrm{cm}^{3}$ \\
Sonic " " & 0.28 & 0.415 & 28 \\
100 mesh rice flour & 0.31 & 0.44 & 19 \\
Defatted rice starch & 0.25 & 0.44 & 25 \\
Soluble starch"i & 0.18 & 0.33 & 7
\end{tabular}

a) Initial rise in viscosity.

b) Alkalinity at the respective points.

c) $10 \%$ Suspension (potato starch).

that of the heat pasting in some starches or treated starches as mentioned above. Difference in the behavior of starch granules with both gelatinization methods may offer a clue of analysis to the structure of starch granule. It will be possible to detect the one from mixed starches because this graph usually shows large difference among starches on the geln. $\mathrm{KOH}$ and has a distinct peak. Moreover, the present apparatus is expected to be applicable, together with amylography and just like titration viscography, for the studies of processing of colloidal foods or polymerization and coagulation of polymers.

\section{REFERENCES}

1) J. A. Radley, "Starch and its Derivatives," Vol. I Chapman \& Hall Ltd., London, 1953, p. 85; H.W. Leach, "Starch Chemistry and Technology,' Vol. I, ed. by R. L. Whistler and E. F. Paschall Academic Press Inc., New York, N.Y., 1965 p. 304.

2) C. E. Mangels and C. H. Bailey, J. Am. Chem. Soc., 55, 1981 (1933).

3) H. Suzuki and N. Taketomi, Kogyo Kagaku Zasshi, 59, 45 (1956).

4) H. Suzuki, ibid., 60, 207, 1051 (1957); Y. Suzuki S. Chikubu and T. Tani, Nippon Nogeikagaku Kaishi, 33, 275 (1959).

5) S. Sato, S. Oka and S. Sigeta, Agr. Biol. Chem. 33, 1134 (1969).

6) C. A. Anker and W. F. Geddes, Cereal Chem. 21. 335 (1944).

7) N. Murayama and Y.Suzuki, Nippon Nogeikagakı Kaishi, 39, 358 (1965).

8) H. Horiuchi and T. Tani, Agr. Biol. Chem., 30 457 (1966).

9) H. Horiuchi and T. Tani, Nippon Nogeikagaki Kaishi, 38, 23 (1964). 